\title{
Family Physicians' Perceptions of Electronic Cigarettes in Tobacco Use Counseling
}

\author{
Samuel Ofei-Dodoo, PhD, MPA, MA, Rick Kellerman, MD, Kari Nilsen, PhD, MA, \\ Ruth Nutting, PhD, LCMFT, and Douglas Lewis, MD
}

Background: Recent support has been shown for physicians to recommend e-cigarettes to patients who are trying to quit smoking. Supporters of this recommendation argue that e-cigarettes are not combustible products and are less harmful and more effective cessation products than regular cigarettes, with less inherent risk. Those who oppose this idea argue that little reliable evidence suggests that e-cigarettes are better cigarette cessation devices than currently available nicotine replacement therapies, and that they pose as much risk as cigarettes. This study was conducted to explore family physicians' perceptions of recommending e-cigarettes as smoking cessation aids to patients who smoke cigarettes.

Methods: The study used a mixed-methods approach whereby a 12-item survey was sent to 154 family physicians throughout the state of Kansas. Data were collected from 117 , a $76 \%$ response rate. A multidisciplinary team used an immersion-crystallization approach to analyze the content of respondents' qualitative data; contingency table analysis was used to evaluate the quantitative data.

Results: The results showed that family physicians have negative perceptions of e-cigarettes and do not recommend them for smoking cessation. Family physicians are concerned about the effectiveness of e-cigarettes and the uncertainty regarding safety.

Conclusions: The results suggest that most family physicians do not recommend e-cigarettes for smoking cessation, citing lack of evidence on effectiveness and uncertainty regarding short- and longterm safety. (J Am Board Fam Med 2017;30:448-459.)

Keywords: Electronic Cigarettes, Family Physician, Kansas, Nicotine, Risk, Smoking Cessation, Surveys and Questionnaires, Uncertainty

Tobacco use remains one of the major preventable causes of morbidity and mortality in the United States, ${ }^{1}$ even though use has decreased significantly over the years. A 2014 report shows that nearly 480,000 deaths per year were associated with tobacco use, and $>16$ million Americans suffered

This article was externally peer reviewed.

Submitted 28 February 2017; revised 7 March 2017; accepted 10 March 2017.

From the Department of Family and Community Medicine, University of Kansas School of Medicine-Wichita (SO-D, RK, KN); and the Family Medicine Residency at Via Christi Hospitals, University of Kansas School of Medicine-Wichita (RN, DL).

Funding: none.

Conflict of interest: none declared.

Corresponding author: Samuel Ofei-Dodoo, PhD, MPA, MA, Research Faculty, Department of Family and Community Medicine, University of Kansas School of MedicineWichita, 1010 N. Kansas, Wichita, KS 67214 (E-mail: sofeidodoo@kumc.edu). from at least 1 smoking-related disease. ${ }^{1}$ In light of these alarming statistics, the number of US adults using tobacco products has declined markedly over the years. For example, between 2005 and 2014, the percentage of US adults aged $\geq 18$ years who used tobacco products declined from nearly $30 \%(\sim 65$ million) in 2005 to nearly $17 \%$ (40 million) in $2014 .^{2}$

As we celebrate the success in reducing the number of US adults who use tobacco products, members of the medical community and public health professionals are receiving and urgent call to increase efforts to continue reducing national tobacco use rates. Nearly 7 of 10 smokers visit their physicians at least once annually, ${ }^{3}$ and they are more likely to quit if their physicians counsel them about the dangers associated with cigarette smoking. ${ }^{4}$ These data suggest that patients who use and depend on tobacco products trust their physicians. 
A study by Meredith and colleagues ${ }^{5}$ found that primary care physicians' favorable attitude toward tobacco counseling was associated with higher rates of smoking cessation behaviors among tobacco users. The findings of this study suggest that primary care physicians have great opportunities to offer smoking cessation intervention to patients who use tobacco products. In addition, the Healthy People 2020 objective regarding tobacco use (objective TU-10.1) is projected to increase tobacco cessation counseling in an office-based ambulatory care setting to $21.1 \%$ from a 2007 baseline of $19.2 \%$ among individuals aged $\geq 18$ years. ${ }^{6}$ To achieve these objectives, primary care physicians have to make tobacco cessation counseling more relevant to the particular patient's diagnosis and lifestyle.

The aforementioned success in tobacco use reduction among US adults is potentially threatened as health care professionals in particular and society as a whole are faced with the increased use of nontraditional tobacco products such as electronic nicotine delivery systems (electronic cigarettes). ${ }^{7,8}$ Throughout this article, the phrase "electronic cigarettes" is used to refer to electronic nicotine delivery systems. Electronic cigarettes, also known as e-cigarettes or vaporizer cigarettes, are battery-operated devices designed to aerosolize nicotine and other chemicals into vapor. ${ }^{9}$ In $2010,1.8 \%$ of US adults reported using e-cigarettes at some point in their lives, compared with $13 \%$ in 2013 . There was a nearly $22 \%$ relative increase $(0.3 \%$ in 2010 to $6.8 \%$ in 2013) in current e-cigarette use during the same period. ${ }^{10}$ Many who support the use of e-cigarette products do so because they see them as smoking cessation aids. ${ }^{11}$

The increased use of e-cigarettes has generated discussion regarding the effectiveness of these products as a smoking cessation intervention. Given the popularity of e-cigarettes among US adults and the large number of smokers who visit a health care professional, there has been support for physicians to recommend e-cigarettes to patients as smoking cessation aids. ${ }^{11}$ Supporters of this recommendation argue that patients who struggle to quit smoking should be encouraged to switch from using regular cigarettes to e-cigarettes, which are not combustion products ${ }^{12}$ and offer users a less harmful way to consume nicotine. ${ }^{11,13}$ For example, e-cigarette advocates such as McNeill and others ${ }^{11,14}$ used a Public Health England report to accentuate that behavioral support together with pharmacotherapy, including e-cigarettes, is an effective way for individuals to quit smoking cigarettes. ${ }^{11,14}$ The call for e-cigarettes as smoking cessation aids has been louder since manufacturers, marketers, and retailers increasingly advertise these products as such, ${ }^{15}$ despite limited reliable data on their effectiveness. ${ }^{16-19}$

Conversely, those who oppose the idea of e-cigarettes as smoking cessation aids have argued that little evidence suggests that e-cigarettes are effective nicotine replacement products, ${ }^{16-19}$ and they have proposed that they are just as unhealthy as smoking tobacco cigarettes. ${ }^{20,21}$ The opposition has also cited a lack of sufficient evidence supporting the effectiveness of e-cigarettes as smoking cessation products. ${ }^{22,23}$

Concern also exists about the potentially deceptive labeling of e-cigarettes. Some reports indicate that the nicotine concentration in some e-cigarettes has been found to be significantly different from the content noted on the label. ${ }^{20}$ In addition, there are concerns about the potential adverse effects of the flavoring in virtually all e-cigarette products. ${ }^{24}$ Inhalation of the derivatives of the flavoring (eg, diacetyl) could, according to Grana and colleagues, ${ }^{24}$ cause respiratory diseases such as bronchiolitis obliterans.

\section{Purposes of the Study}

Given the arguments above that (1) most tobacco users visit their primary care providers at least once annually, and that patients are more likely to quit smoking if advised by their a physicians; (2) limited evidence indicates the effectiveness of e-cigarettes as smoking cessation aids; and (3) there are opposing views on whether e-cigarettes should be recommended as pharmacotherapy, this study seeks to explore family physicians' perceptions of recommending e-cigarettes to patients who smoke cigarettes. Specifically, the study seeks to collect information related to the following questions:

1. Do family physicians recommend e-cigarettes for smoking cessation? If so, why?

2. Is there a relation between family physicians' career status (ie, actively practicing physician, faculty physician, or resident-physician) and their decisions to recommend to patients the use of e-cigarettes for tobacco cessation? We hypothesize that resident-physicians are less likely 
to recommend e-cigarettes as smoking cessation aids than are faculty physicians and actively practicing physicians.

3. What are family physicians' opinions on the effectiveness of e-cigarettes as smoking cessation aids?

\section{Methods}

\section{Study Design}

The study used a mixed method approach ${ }^{25}$ (integrating both qualitative and quantitative questions) to collect, analyze, and interpret the data. The goal of using this approach was to obtain a better understanding of the study results and to ensure that there were no gaps in the data collected. The quantitative approach allowed us to obtain value-free and objective insights into the opinions of respondents about e-cigarettes, while the qualitative approach allowed for an in-depth understanding of those insights.

The study relied on family physicians who are in active practice, faculty, and residents of the 3 family medicine residencies sponsored by the Department of Family and Community Medicine (DFCM) at the University of Kansas School of MedicineWichita (KUSM-W). The physicians, faculty, and resident-physicians were asked to complete a questionnaire about their perceptions of recommending e-cigarettes as a cessation aid to patients who use tobacco products. The KUSM-W Institutional Review Board approved the study protocol before its implementation.

\section{Participants and Study Instrument}

To measure participants' perceptions of recommending e-cigarettes to patients for tobacco cessation, a 12-item survey questionnaire was developed (see the Appendix). Several information sources were used to generate and select the items. First, the items were created based on the literature on e-cigarettes. ${ }^{11,20,21,26}$ The questions generated were reviewed by 2 family physicians and a behavioral scientist, based on their experiences working with tobacco users, to ensure that the questions had face validity. We later sought input from faculty and staff of the KUSM-W DFCM, who ensured that the questions were intuitively understandable.

The survey questionnaire was hosted on SurveyMonkey, and a generated link was sent via E-mail to potential participants. The DFCM uses an
E-mail system called Family Medicine Research and Data Information Office as a survey collection tool; this system is an electronic practice-based research network comprising family physicians throughout the state of Kansas who are KUSM-W Family Medicine Residency program graduates, actively practicing family physician nongraduates, faculty physicians, and resident-physicians. The link was initially sent to 154 family physicians, faculty, and resident-physicians. Two reminders were subsequently sent to those who had not completed the survey. Of the 154 participants in the study sample, data were collected from 117, a $76 \%$ response rate.

\section{Participant Characteristics}

As shown in Table 1, all the respondents were adults, aged 25 to $\geq 65$ years; the majority were between 25 and 34 years old. Of all the respondents

\section{Table 1. Demographic Profile of Participants}

\begin{tabular}{lc}
\hline Demographics & Measure \\
\hline Sex* & \\
Male & $53.3(57)$ \\
Female & $46.7(50)$ \\
Age* (years) & \\
Range & 25 to $\geq 65$ \\
$18-24$ & $0(0)$ \\
$25-34$ & $55.1(60)$ \\
$35-44$ & $21.5(23)$ \\
$45-54$ & $12.2(13)$ \\
$55-64$ & $6.5(7)$ \\
$\geq 65$ & $3.7(4)$ \\
Career status* & \\
Actively practicing family physician & $25.2(27)$ \\
Full-time faculty & $23.4(25)$ \\
Resident-physician & $51.4(55)$ \\
Years in practice (n) & \\
Range & 3 to 38 years \\
Mean (SD) & $21(10.9)$ \\
Years as a full time faculty (n) & \\
Range & 2 months to 22 \\
Mean (SD) & years \\
Postgraduate year of residency & $8.2(6.6)$ \\
1 & \\
2 & $32.7(18)$ \\
3 & $36.4(20)$ \\
\hline & $30.9(17)$ \\
\hline
\end{tabular}

Data are \% (n) unless otherwise indicated.

*Some responses were missing.

$\mathrm{SD}$, standard deviation. 
who provided their sex $(8.7 \%$ of the sample chose not to provide this information), $53.3 \%$ were male and $46.7 \%$ were female. Of the respondents who provided their career status, more than half (51.4\%) were physician-residents. The mean (standard deviation) years of experience among the actively practicing physicians in the sample was 21 (10.9). A total of 107 respondents provided their career status, of whom $19(\sim 18 \%)$ reported that they recommend or have recommended e-cigarettes for tobacco cessation; the majority of these were actively practicing physicians (Figure 1).

\section{Data Analysis}

Some of the qualitative data collected were converted into narratives that were analyzed qualitatively, while the rest of the data were converted into numeric codes and statistically analyzed. ${ }^{25}$ To determine whether respondents' decision to recommend e-cigarettes as a smoking cessation aid was due to their career status, a contingency table was calculated. The study team used an immersion-crystallization approach ${ }^{27-30}$ to analyze the content of respondents' open-ended responses (qualitative data). This multidisciplinary team comprised 2 community psychologists (SO-D, KN), 2 family physicians (RK, DL), and a behavioral scientist $(\mathrm{RN})$.

\section{Results}

\section{Quantitative Results}

The majority of respondents (82\%) indicated they do not recommend the use of e-cigarettes for smoking cessation, and they listed several reasons for their decisions (these are discussed later in the article). A 2-way contingency table analysis was conducted to evaluate whether the physicians' career status (being practicing family physicians, faculty physicians, or resident-physicians) influenced their decision to recommend e-cigarettes for smoking cessation (yes or no). Career status and respondents' decision to recommend e-cigarettes were found to be significantly related $\left(\chi^{2}[2, \mathrm{n}=191]=\right.$ 8.44; $P=.015$; Cramer $V=0.21$ ) (Table 2). The proportions of faculty physicians, practicing physicians, and resident-physicians who did not recommend e-cigarettes for tobacco cessation were 0.89 , 0.80 , and 0.95 respectively.

Follow-up pairwise comparisons were conducted to evaluate the difference among these proportions. Table 3 shows the results of these analyses. The Holm sequential Bonferroni method was used to control for type I error at the 0.05 level across all 3 comparisons. The only significant pairwise difference was between practicing physicians and resident-physicians. The probability of e-cigarettes not being recommended for smoking cessation was 1.19 times $(0.95 / .80)$ more likely when the medical professional was a resident-physician as opposed to an actively practic-

Figure 1. Career status of respondents who recommended and those who did not recommend e-cigarettes (E-cig).

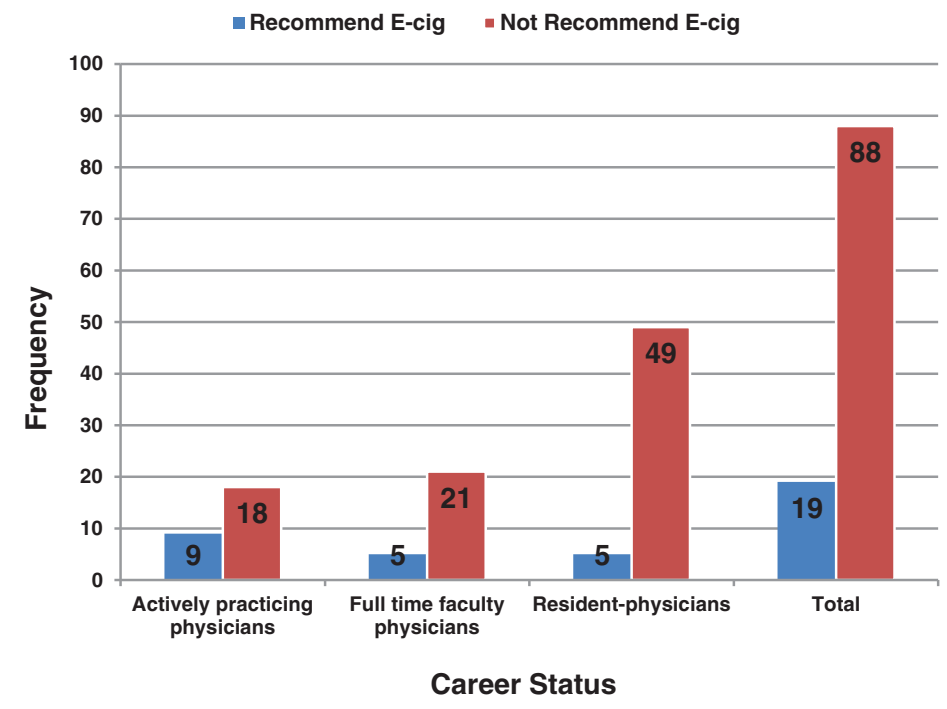


Table 2. Results of $\chi^{2}$ Test and Descriptive Statistics for Physicians' Career Status by E-Cigarettes Recommendation

\begin{tabular}{|c|c|c|c|}
\hline \multirow[b]{2}{*}{ Career Status } & \multicolumn{3}{|c|}{ Recommending E-Cigarettes } \\
\hline & Yes & No & Total \\
\hline \multicolumn{4}{|l|}{ Practicing physicians } \\
\hline Count & 9 & 36 & 45 \\
\hline Expected count & 4.5 & 40.5 & 45.0 \\
\hline Percentage within Career status & 20.0 & 80.0 & 100.0 \\
\hline \multicolumn{4}{|l|}{ Full-time faculty-physician } \\
\hline Count & 5 & 40 & 45 \\
\hline Expected count & 4.5 & 40.5 & 45.0 \\
\hline Percentage within Career status & 11.1 & 88.9 & 100.0 \\
\hline \multicolumn{4}{|l|}{ Resident-physician } \\
\hline Count & 5 & 96 & 101 \\
\hline Expected count & 10.0 & 91.0 & 101.0 \\
\hline Percentage within Career status & 5.0 & 95.0 & 100.0 \\
\hline \multicolumn{4}{|l|}{ Total } \\
\hline Count & 19 & 172 & 191 \\
\hline Expected count & 19.0 & 172.0 & 191.0 \\
\hline Percentage within Career status & 9.9 & 90.1 & 100.0 \\
\hline
\end{tabular}

$\chi^{2}=8.44(P=.015) ; \mathrm{df}=2 ;$ Cramer $V=0.21$.

ing physician. What follows is a discussion of the qualitative results.

\section{Qualitative Results: Those Who Recommend E-Cigarettes}

Of the 117 respondents, $18 \%$ indicated they do recommend e-cigarettes for smoking cessation. Two themes emerged from the analysis of responses regarding their reasons: e-cigarettes serve as a bridge for smokers to quit smoking cigarettes, and e-cigarettes are the lesser of 2 evils. In other words, e-cigarettes were felt to be relatively safer than regular cigarettes. Each theme is discussed in detail in the subsequent sections.

\section{A Bridge to Quitting Smoking Cigarettes}

Most of the responses ( $\sim 60 \%)$ regarding recommending e-cigarettes for smoking cessation demonstrated a belief that the products serve as step- ping stone to smoking cessation. Dr. A stated, "the patient suggested it and I felt that their chance at complete cessation would be increased in this 'step down' way." Dr. B explained, “initially, I felt this could be another method to enable patients to stop smoking. It was first reported to me by patients who had tried it with some success."

Some participants also felt that the use of e-cigarettes helped smokers deal with oral (handto-mouth) fixations associated with smoking. Dr. C wrote, "I have recommended the non-nicotine water vapor type as a substitute to help patients with the oral fixation, hand to mouth need that smoking provides for them. It also provides a vapor that you breathe in and out deeply which mimics the relaxing effect deep breathing provides a smoker.”

Table 3. Results for Pairwise Comparisons Using the Holm Sequential Bonferroni Method

\begin{tabular}{lccc}
\hline Comparison & Pearson $\chi^{2}$ & $P$ value $(\alpha)$ & Cramer $V$ \\
\hline Practicing physicians vs faculty physicians & 1.35 & $.24(0.050)$ & 0.12 \\
Practicing physicians vs resident-physicians & $8.64^{*}$ & $.003(0.025)$ & 0.24 \\
Faculty physicians vs resident-physicians & 2.04 & $.15(0.017)$ & 0.11 \\
\hline
\end{tabular}

${ }^{*} P$ value $\leq \alpha$. 


\section{Lesser of Two Evils}

Over $40 \%$ of participants' responses regarding recommending e-cigarettes for smoking cessation fell under the "lesser of 2 evils" theme. Even though these respondents recognized the presumed harmful effects associated with the use of e-cigarettes, they thought the gravity of such effects is less than those of smoking regular cigarettes. e-Cigarettes also offer users the chance to quit smoking ignitable cigarettes. For some respondents, e-cigarettes contain fewer chemicals than regular cigarettes and therefore are perceived to have few to no risks. Dr. $\mathrm{D}$ wrote, "it [e-cigarette] is probably bad for you, but we do not know how bad. It is vapor. We do know that smoking tobacco kills ... you. So lesser of 2 evils [sic].”

Some respondents believed that electronic nicotine delivery devices are able to remove all the harmful chemicals from the products, making them less harmful to users. Dr. E explained his reason for recommending e-cigarettes as smoking cessation aids to patients: "[they] can immediately eliminate all the harmful chemicals other than nicotine. [E-cigarettes] can be used to taper nicotine just like patches, gum, etc. [They] provide tactile satisfaction that is so much a part of cigarette smoking."

Likewise, some respondents believed e-cigarettes have fewer carcinogenic effects. Dr. F explained, "e-cigarettes have no to little cancer risk compared with cigarettes." Dr. G's response reemphasized the aforementioned reason: "the use is less risky for cancer even though the cardiovascular risk is still probably high."

\section{Qualitative Results: Those Who Do Not Recommend E-Cigarettes}

Nearly $82 \%$ of the 117 respondents indicated they do not recommend e-cigarettes for smoking cessation. Five interconnected themes emerged from the analysis of reasons for not recommending e-cigarettes: no data support the effectiveness of e-cigarettes, they are just as bad as combustible cigarettes or are not beneficial, they are not approved by the US Food and Drug Administration (FDA), better options are available, and other reasons. The following is a discussion of the themes mentioned by participants who do not recommend e-cigarettes for smoking cessation.
Lack of Data to Support the Efficacy of E-Cigarettes

Most of the respondents who opposed the use of e-cigarettes as a smoking cessation aid commented on the lack of data supporting the usefulness of the devices in helping cigarette smokers to quit. Some respondents thought e-cigarettes do nothing to help people break their behavior, as e-cigarettes still contain nicotine. Therefore, they felt that ecigarettes are not effective for smoking cessation. Dr. $\mathrm{H}$ argued, "e-cigarettes still provide nicotine and continue to encourage physiologic addiction to that chemical." This sentiment was also shared by Dr. I, who explained, "[there] are not enough data on outcomes to recommend them [e-cigarettes]." "There is not significant evidence showing e-cigarettes are effective in assisting in tobacco cessation," Dr. J explained. "No data to support use as a smoking cessation aid," Dr. K emphasized.

Some respondents called for more studies into the effectiveness of e-cigarettes before allowing them to be used as smoking cessation products. Dr. L suggested, "No, there needs to be more studies that are larger and randomized trials to conclude benefit. People do not get off the e-cigarettes and some use both [e-cig and regular cigarettes] and sometimes they smoke the e-cigarettes more than the regular cigarettes."

\section{E-Cigarettes Are Just as Bad as Smoking Combustible Cigarettes}

A good number of the responses indicated no reliable evidence suggests that e-cigarettes are a healthier replacement, and that they are just as bad as smoking regular cigarettes. Dr. M argued, "[it is] not proven that they [e-cigarettes] are any better for health than cigarettes." Dr. N explained his reason for not recommending e-cigarettes as, "I am afraid they [patients] would not make the same effort to quit the e-cigarette because they think it is better than smoking." These feelings were also shared by Dr. O: "I think they [e-cigarettes] are just as bad."

\section{Safety and Not Approved by the FDA}

Insufficient data on safety regarding the use of e-cigarettes was a major factor that influenced respondents' reasons for not recommending the electronic devices for smoking cessation. Respondents voiced concerns about the effects of heated vapor as well as the unregulated, flavored liquids used in the 
devices. Dr. P argued, "there is not enough information or studies proving the safety or effectiveness of using them for smoking cessation.” Dr. Q's response typified concerns about heated vapor: "[I have] concern about effects of heated vapor." "[There is] no proven benefit with uncontrolled liquids" (Dr. R).

Others highlighted that until and unless the FDA approves specific e-cigarettes as safe and effective for use as tobacco cessation aids, they will not recommend their use for smoking cessation. Dr. S stated, "[they are] not FDA approved, no studies that I am aware of that shows [sic] they [e-cigarettes] help with smoking cessation." "[They are] not regulated by [the] FDA and this seems to be a dangerous thing with possible carcinogenic effects," expressed Dr. T.

\section{Availability of Better Options}

Some of the respondents argued that better and more effective smoking cessation products than e-cigarettes are available and would rather recommend those for smoking cessation. Dr. U stated, "I believe other recommendations are more efficacious." "I recommend nicotine replacement products, not tobacco replacement products. Plus I am uncertain of the risks associated with e-cigarettes nor do I have any knowledge of any literature in using them for smoking cessation," explained Dr. V.

\section{Other Reasons}

Respondents who opposed the use of e-cigarettes also stressed that the devices are not effective in breaking the smoking behavior. This stance was shared by Dr. W, who stated: "They [e-cigarettes] do nothing to help a person break the behavior of smoking. Many of them still have nicotine. They are not effective for smoking cessation." Others were concerned about possible side effects associated with the use of e-cigarettes. Dr. X stated her reason for not recommending the devices to her patients who smoke: "[They are] not well studied. [There are] multiple possibilities for adverse effects." "I believe it still has negative effects on the lungs," said Dr. Y. Others who stated their decisions for not recommending e-cigarettes as smoking cessation aids were influenced by the professional organizations with which they are affiliated. For example, Dr. Z stated: "I do not officially recommend them, because that is the AAFP's
[American Academy of Family Physician's] stance/ guideline. However, I think e-cigarettes are vastly healthier and can lead to cessation [sic]."

\section{Effectiveness of E-Cigarettes for Tobacco Smoking Cessation}

The results presented here come from the qualitative data of responses to research question 4 (see the Appendix), where respondents explained whether e-cigarettes are effective cessation aids. Participants' responses were rated using a 6-point scale that ranged from 1 ("very effective") to 6 ("very ineffective") and 0 ("not sure"). Overall, the results showed that the respondents thought e-cigarettes were ineffective in helping patients quit smoking $(4.5 \pm 1.4)$. Of the participants, 100 responded to the question regarding the effectiveness of e-cigarettes: $46 \%$ of them thought e-cigarettes were either ineffective or very ineffective (Table 4). Even some of the respondents who recommend or have recommended e-cigarettes to patients thought the devices were either ineffective or very ineffective $(43 \%)$ for smoking cessation (Figure 2). Most of these respondents' reasons were based on personal experiences working with patients who had used or were using e-cigarettes for smoking cessation. A common theme that emerged was that e-cigarettes do not help patients quit using tobacco products; rather, they offered patients another delivery mechanism to be addicted to nicotine.

While more than a third (35\%) of the respondents was not sure about the effectiveness of e-cigarettes, only $12 \%$ thought the devices were either very effective or effective smoking cessation products (Table 4). Their responses suggested e-ciga-

\section{Table 4. Respondents' Opinions About the Effectiveness of E-Cigarettes*}

\begin{tabular}{lc}
\hline Responses & Respondents, $\mathrm{n}(\%)$ \\
\hline Very effective & $5(5)$ \\
Effective & $7(7)$ \\
Neutral & $7(7)$ \\
Ineffective & $27(27)$ \\
Very ineffective & $19(19)$ \\
Not sure & $35(35)$ \\
Total & $100(100)$ \\
\hline
\end{tabular}

*Some participants did not provide responses. Scores ranged from 1 (very effective) to 5 (very ineffective) and 0 (not sure). Mean effectiveness score, 4.5 ; standard deviation of effectiveness score, 1.4 . 
Figure 2. Respondents' perceptions of the effectiveness of e-cigarettes (E-cig).

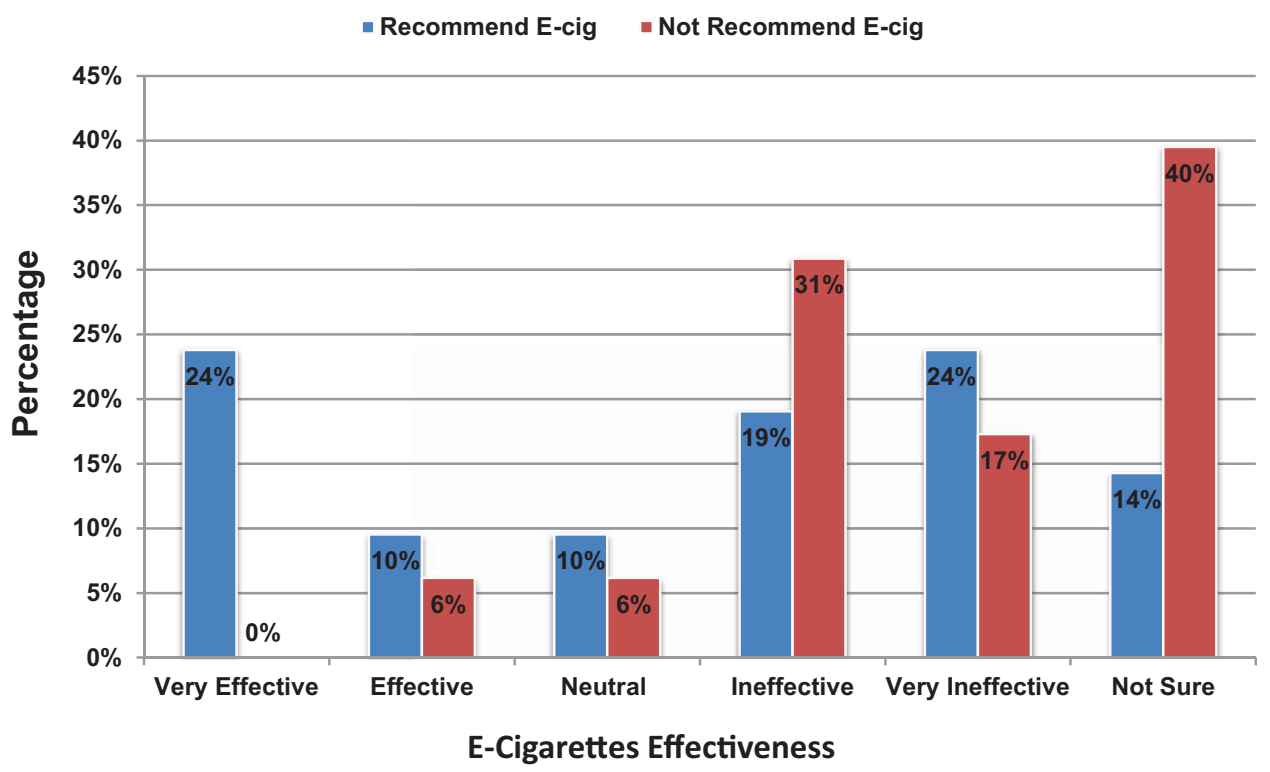

rettes might be just as effective as other FDAapproved smoking cessation options on the market. ${ }^{14,15}$ "I've seen several patients quit tobacco with e-cigs. I'd say they are better than the $\mathrm{Rx}$ [prescription] options on the market in my experience," said Dr. ZZ. This sentiment is also shared by McNeill, ${ }^{11}$ who argued that many smokers have tried unsuccessfully to quit smoking with some of the approved treatments found to be effective.

\section{Discussion}

The findings of this study demonstrate that most family physicians have negative perceptions of e-cigarettes as smoking cessation aids. Our data suggest that family physicians are not only unconvinced about the effectiveness of e-cigarettes as smoking cessation devices; they are also concerned about the uncertainty regarding the short- to long-term safety of the products. These findings suggest that clinicians (in general) and family physicians (in particular) should recommend against the use of electronic cigarettes. The results are particularly important for primary care physicians, who are the key players in helping the nation to achieve the Healthy People 2020 objectives regarding tobacco use.

The first purpose of this study was to determine whether family physicians recommended e-cigarettes for smoking cessation. The results showed the majority $(82 \%)$ of respondents did not recommend e-cigarettes for smoking cessation, and their reasons were multifactorial. They cited lack of data supporting effectiveness, uncertainty regarding safety, lack of government regulation, evidence of toxic chemical content, and better options (such as Chantix) as the major reasons for not recommending e-cigarettes for smoking cessation. These concerns are shared by major medical and health organizations like the American Academy of Family Physicians, ${ }^{21}$ the American Medical Association, ${ }^{31}$ the American College of Physicians, ${ }^{32}$ the American Public Health Association, ${ }^{33}$ and the World Health Organization. ${ }^{34}$

Our findings showed that $18 \%$ of the respondents recommend or have recommended electronic cigarettes to their patients who smoke. This percentage is smaller than the findings of a study of 128 North Carolina physicians, of whom $35 \%$ have recommended electronic cigarettes to their patients who smoke. ${ }^{35}$ Interestingly, the small number of family physicians in Kansas who have and do recommend e-cigarettes as cessation aids indicated their awareness of harmful effects associated with the use of any tobacco products, but they believed that e-cigarettes are less harmful. This assertion is consistent with the recommendation by Fiore and colleagues $^{12}$ that until more evidenced-based studies are conducted to inform the clinical decisionmaking process, physicians should encourage the use of less harmful products such as e-cigarettes to patients who use combustible tobacco products. 
The second purpose of the study was to determine whether family physicians' decision to recommend e-cigarettes to patients for smoking cessation was influenced by their career status (ie, practicing physicians, faculty physicians, or resident-physicians). Our findings showed a significant relationship between career status and the respondents' decision to recommend e-cigarettes to patients: $80 \%$ of practicing physicians, compared with $89 \%$ of faculty physicians and $95 \%$ of resident-physicians, did not recommend e-cigarettes to patients. The respondents' reasons for their stances were explained earlier. These reasons could be influenced by the positions taken by major medical and health organizations encouraging their members to recommend only evidence-based smoking cessation products to patients until more reliable data are available on the effectiveness and safety of e-cigarettes. ${ }^{21,31-34}$ For example, a resident-physician indicated that her decision not to recommend e-cigarettes for smoking cessation was influenced by the stance of the American Academy of Family Physicians on the use of the devices as cessation aids.

Further analysis to determine the difference among the proportions showed there was a significant difference between practicing physicians and resident-physicians regarding their recommendation of e-cigarettes. Compared with practicing physicians, resident-physicians were less likely to recommend e-cigarettes to patients. These findings are consistent with other findings that showed that a lack of evidence-based data on the effectiveness and long-term safety concerns were the major reasons for resident-physicians' reluctance in recommending e-cigarettes in clinical practice. ${ }^{36,37}$

Finally, in seeking to determine family physicians' opinions regarding the effectiveness of e-cigarettes, our findings suggest that family physicians are concerned about the effectiveness of e-cigarettes as cessation devices. These findings are consistent with concerns echoed by many studies that have shown clinicians misgivings about the effectiveness of the devices. ${ }^{20,21,26,31-34}$ Interestingly, more than a third of the respondents were unsure about the effectiveness of e-cigarettes, indicating that family physicians are concerned about the uncertainty regarding the efficacy of e-cigarettes as substitutes for cigarette smoking. ${ }^{38}$

\section{Future Studies}

This study involved family physicians throughout the state of Kansas who are KUSM-W Family Medicine Residency program graduates, practicing physicians who were not KUSM-W graduates, faculty physicians, and resident-physicians. The small sample size limits the generalizability of the findings. A similar study should be conducted with a larger and more diverse sample that includes family physicians from other states. A more diverse sample will lead to a better understanding of clinicians' perceptions of e-cigarettes in tobacco use counseling. Better still, more reliable, evidence-based studies need to be performed to inform clinical decision making regarding the effectiveness of e-cigarettes for tobacco cessation.

\section{Conclusions}

As health care providers, physicians are considered "credible sources of advice and support," 11 and are more likely than other health care providers to succeed in helping patients quit using tobacco products. Our data suggest that most family physicians do not recommend e-cigarettes to patients for smoking cessation, citing a lack of evidence for effectiveness and uncertainty regarding short- to long-term safety.

Family physicians' efforts in helping patients quit smoking should center on the proven best practices, including behavioral support and FDAapproved pharmacotherapy. Until more reliable studies are done on the efficacy, quality, and safety of e-cigarettes, family physicians should consider recommending only evidence-based smoking cessation products to patients. They can also help patients to achieve cessation by referring them to behavioral health providers and state-sponsored quit lines. Evidence-based cessation approaches such as advice from physicians and behaviorists, quit-line counseling, and FDA-approved pharmacotherapies, ${ }^{39}$ together with social support, should be encouraged.

The authors thank Julie Galliart and Lori Beasley for their help during survey development.

To see this article online, please go to: http://jabfm.org/content/ 30/4/448.full.

\section{References}

1. U.S. Department of Health and Human Services. The health consequences of smoking - 50 years of 
progress. A report of the surgeon general. Atlanta: GA: U.S. Department of Health and Human Services, Centers for Disease Control and Prevention, National Center for Chronic Disease Prevention and Health Promotion, Office on Smoking and Health; 2014.

2. Centers for Disease Control and Prevention. Current cigarette smoking among adults-United States, 2005-2014. Morb Mortal Wkly Rep 2015;64: 1233-40.

3. Fiore M. Treating tobacco use and dependence: 2008 update: Clinical practice guideline. Rockville, MD: Agency for Healthcare Research and Quality; 2013. Available from: https://www.ahrq. gov/professionals/clinicians-providers/guidelinesrecommendations/tobacco/clinicians/update/index. html. Accessed June 19, 2017.

4. Stead LF, Buitrago D, Preciado N, Sanchez G, Hartmann-Boyce J, Lancaster T. Physician advice for smoking cessation. Cochrane Database Syst Rev 2013;(5):CD000165.

5. Meredith LS, Yano EM, Hickey SC, Sherman SE. Primary care provider attitudes are associated with smoking cessation counseling and referral. Med Care 2005;43:929-34.

6. US Department of Health and Human Services. Tobacco use objectives. Healthy People 2020. Washington, DC: US Department of Health and Human Services; 2011. Available from: https:// www.healthypeople.gov/2020/topics-objectives/ topic/tobacco-use. Accessed February 26, 2017.

7. King BA, Alam S, Promoff G, Arrazola R, Dube SR. Awareness and ever-use of electronic cigarettes among U.S. adults, 2010-2011. Nicotine Tob Res 2013;15:1623-7.

8. King BA, Dube SR, Tynan MA. Flavored cigar smoking among U.S. adults: findings from the 20092010 National Adult Tobacco Survey. Nicotine Tob Res 2013;15:608-14.

9. U.S. Department of Health \& Human Services. Electronic cigarettes. Available from: http:// betobaccofree.hhs.gov/about-tobacco/ElectronicCigarettes/. Accessed September 12, 2016.

10. McMillen RC, Gottlieb MA, Shaefer RM, Winickoff JP, Klein JD. Trends in electronic cigarette use among U.S. adults: use is increasing in both smokers and nonsmokers. Nicotine Tob Res 2015;17:1195202.

11. McNeill A. Should clinicians recommend e-cigarettes to their patients who smoke? Yes. Ann Fam Med 2016;14:300-1.

12. Fiore MC, Schroeder SA, Baker TB. Smoke, the chief killer-strategies for targeting combustible tobacco use. N Engl J Med 2014;370:297-9.

13. Tobacco Advisory Group of the Royal College of Physicians. Nicotine without smoke-tobacco harm reduction. April 28, 2016. London: Royal College of Physicians. Available from: https://www.rcplondon. ac.uk/projects/outputs/nicotine-without-smoketobacco-harm-reduction-0. Accessed September 16, 2016.

14. McNeill A, Brose LS, Calder R, Hitchman SC, Hajek P, McRobbie H. E-cigarettes: an evidence update. Public Health England. Published August 19, 2015; updated August 28, 2015. Available from: https://www.gov.uk/government/publications/ e-cigarettes-an-evidence-update. Accessed September 26, 2016.

15. Paek HJ, Kim S, Hove T, Huh JY. Reduced harm or another gateway to smoking? Source, message, and information characteristics of e-cigarette videos on YouTube. J Health Commun 2014;19:54560.

16. Adkison SE, O'Connor RJ, Bansal-Travers M, et al. Electronic nicotine delivery systems: international tobacco control four-country survey. Am J Prev Med 2013;44:207-15.

17. Brown J, Beard E, Kotz D, Michie S, West R. Realworld effectiveness of e-cigarettes when used to aid smoking cessation: a cross-sectional population study. Addiction 2014;109:1531-40.

18. Popova L, Ling PM. Alternative tobacco product use and smoking cessation: a national study. Am J Public Health 2013;103:923-30.

19. Bullen C, Howe C, Laugesen M, et al. Electronic cigarettes for smoking cessation: a randomised controlled trial. Lancet 2013;382:1629-37.

20. Meernik C, Goldstein AO. Should clinicians recommend e-cigarettes to their patients who smoke? No. Ann Fam Med 2016;14:302-3.

21. American Academy of Family Physicians. E-cigarettes-an emerging health hazard. In: Tobacco: preventing and treating nicotine dependence and tobacco use (position paper), 2014. Available from: http://www.aafp.org/about/policies/all/nicotinetobacco-prevention.html\#E-Cigarettes-An Emerging Health Hazard. Accessed September 12, 2016.

22. US Preventive Services Task Force. Tobacco smoking cessation in adults, including pregnant women: behavioral and pharmacotherapy interventions. Released September 2015. Available from: https://www. uspreventiveservicestaskforce.org/Page/Document/ UpdateSummaryFinal/tobacco-use-in-adults-andpregnant-women-counseling-and-interventions 1 . Accessed September 12, 2016.

23. Kalkhoran S, Glantz SA. E-cigarettes and smoking cessation in real-world and clinical settings: a systematic review and meta-analysis. Lancet 2016;4: 116-28.

24. Grana R, Benowitz N, Glantz SA. E-cigarettes: a scientific review. Circulation 2014;129:1972-86.

25. Creswell JW. Mapping the developing landscape of mixed methods research. In: Tashakkori A, Teddlie C, eds. Sage handbook of mixed methods in social \& behavioral research, 2nd ed. Thousand Oaks, CA: Sage; 2010: 45-68. 
26. Are e-cigarettes a healthy way to quit smoking? Supporters say they appear to be effective. Critics say there are better and safer ways to quit smoking. Wall Street Journal, April 11, 2016. Available from: http:// www.wsj.com/articles/are-e-cigarettes-a-healthyway-to-quit-smoking-1460340169. Accessed August 2, 2016.

27. Borkan, J. “Immersion/crystallization.” In: Crabtree BF, Miller WL, eds. Doing qualitative research, 2nd ed. Thousand Oaks, CA: Sage Publications; 1999: 179-94.

28. Miller WL, Crabtree BF. Primary care research: a multimethod typology and qualitative roadmap. In: Crabtree BF, Miller WL, eds. Doing qualitative research. Newbury Park, CA: Sage Publication; 1992: $3-28$.

29. Miller WL, Crabtree BF. Clinical research. In: Denzin NK, Lincoln YS, eds. Handbook of qualitative research. Thousand Oaks, CA: Sage Publications; 1994: 340-52.

30. Miller WL, Crabtree BF. Qualitative analysis: how to begin making sense. Fam Pract Res J 1994;14: 289-97.

31. American Medical Association. AMA strengthens policy on electronic cigarettes to further protect youth. Position paper, June 9, 2015. Available from: http://www.ama-assn.org/ama/pub/news/news/ 2015/2015-06-09-ama-policy-protect-youth.page. Accessed September 12, 2016.

32. Crowley RA. Electronic nicotine delivery systems: executive summary of a policy position paper from the American College of Physicians. Ann Intern Med 2015;162:583-4.

33. American Public Health Association. Supporting regulation of electronic cigarettes. Policy no. 20149. November 18, 2016. Available from: https:// www.apha.org/policies-and-advocacy/public-healthpolicy-statements/policy-database/2015/01/05/12/ 58/supporting-regulation-of-electronic-cigarettes. Accessed September 16, 2016.

34. World Health Organization. Electronic cigarettes (e-cigarettes) or electronic nicotine delivery systems. Revised March 30, 2015. Available from: http:// www.who.int/tobacco/communications/statements/ eletronic_cigarettes/en/. Accessed September 16, 2016.

35. Kandra KL, Ranney LM, Lee JG, Goldstein AO. Physicians' attitudes and use of e-cigarettes as cessation devices, North Carolina, 2013. PLoS One 2014; 9:e103462.

36. Egnot E, Jordan K, Elliott JO. Associations with resident physicians' early adoption of electronic cigarettes for smoking cessation. Postgrad Med J 2017; 93:319-25.

37. Pepper JK, McRee AL, Gilkey MB. Healthcare providers' beliefs and attitudes about electronic cigarettes and preventive counseling for adolescent patients. J Adolesc Health 2014;54:678-83.
38. Heartmann-Boyce J, McRobbie H, Bullen C, Begh R, Stead LF, Hajek P. Electronic cigarettes for smoking cessation. Cochrane Database Syst Rev 2016;(14):CD010216.

39. Fiore MC, Baker TB. Treating smokers in the health care setting. N Engl J Med 2011;365:1222-31.

\section{Appendix \\ Physicians' Perceptions of Electronic Cigarettes Survey}

The Department of Family and Community Medicine-Wichita is conducting a survey of family physicians and KUSM-Wichita family medicine residents to measure attitudes and knowledge about electronic cigarettes. The survey will take approximately 5 minutes to complete. Your participation is voluntary, and your responses will remain confidential. Your decision to participate will not in any way affect your standing at KUSM-Wichita now or in the future. If you have any questions, please contact Dr. Samuel Ofei-Dodoo at sofeidodoo@kumc.edu or Dr. Rick Kellerman at rkellerm@kumc.edu.

The following set of questions seeks to assess your opinions regarding recommending electronic cigarettes to patients who smoke.

1. Do you, or have you, recommended electronic cigarettes for smoking cessation?
a. Yes
b. No
Why or why not?

2. Would you recommend electronic cigarettes to a patient who cannot, or does not, want to stop smoking?
a. Yes
b. No
Why or why not?

3. Some recent studies have documented that many smokers are now using electronic cigarettes as a way to quit smoking tobacco. What do you think about electronic cigarettes being one of the most popular, nonprescription methods for smokers trying to quit?

4. In your opinion, how effective are electronic cigarettes in helping smokers to quit? Please explain.

5. Do you know of any adverse short-term effects of electronic cigarettes use? If so, please list the effects.

6. In your opinion, what are some of the adverse long-term effects of electronic cigarettes use? 
The following set of questions asks about your demographic profile.

7. What is your current age? (Please select the range into which your age falls.)
a. 18 to 24 years
b. 25 to 34 years
c. 35 to 44 years
d. 45 to 54 years
e. 55 to 64 years
f. $\geq 65$

8. What is your gender? (Please select one.)
a. Male
b. Female
c. Other (please specify)

9. I am a ...
a. Full time practicing family physician
b. Full-time faculty
c. Resident-physician
d. Fellow
e. Other (please specify)

10. What is the number of years since you graduated from residency?

11. How long have you been a full time faculty?

12. What is your current year in residency?
a. PGY 1
b. PGY 2
c. PGY 3

Thanks for your participation! 